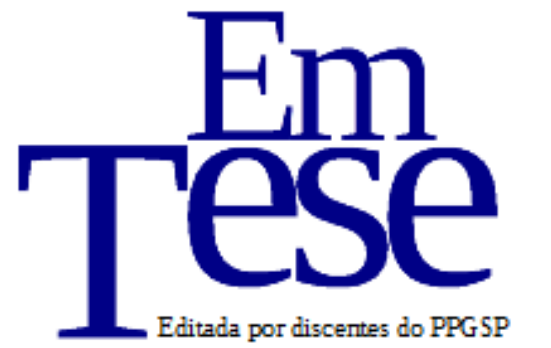

UFSC

PPG SP PROG RAMA DE

POS-GRADUAÇAOO EM

Sociologia

Política

V. 15 , n. 2 p. 01 , Julho, 2018.

DOI: http://dx.doi.org/10.5007/1806-5023.2018v15n2p315

\title{
Neomarxismos e Teoria do Discurso: diálogos e embates entre Ernesto Laclau e Slavoj Žižek ${ }^{1}$
}

George Zeidan Araújo²

Resumo: O objetivo deste trabalho é apresentar os principais elementos que compõem as teorizações sobre o discurso político presentes no pensamento de Ernesto Laclau e Slavoj Žižek para, a partir disso, delinear alguns dos diálogos e embates que suas posições suscitaram no que diz respeito ao discurso político e à prática política.

Palavras-chave: Laclau. Žižek. Neomarxismos. Teoria do discurso.

\section{Neomarxismos and Discourse Theory: dialogues and clashes between Ernesto Laclau and Slavoj Žižek}

Abstract: The aim of this paper is to present the main elements that form the theoretical reflection on political discourse in the thinking of Ernesto Laclau and Slavoj Žižek, in order to outline some of the dialogues and confrontations that their positions raised regarding the political discourse and the political practice.

Keywords: Laclau. Žižek. Neo-Marxisms. Theories of Discourse.

\footnotetext{
1 (cc) EY Esta obra está licenciada com uma Licença Creative Commons Atribuição 4.0 Internacional.

${ }^{2}$ Doutor em História pela Universidade Federal de Santa Catarina. E-mail: geozaraujo@gmail.com
} 


\section{Introdução}

Atualmente, discurso é um dos conceitos mais utilizados na filosofia e no conjunto das ciências humanas e sociais. Apesar (ou talvez por causa) disso, há uma enorme quantidade de definições do que seria discurso, algumas delas conflitantes ou sobrepostas, formuladas através das mais diversas perspectivas teóricas e disciplinares. $\mathrm{Na}$ linguística, o termo geralmente é usado como uma amostra dos diferentes tipos de linguagem (falada ou escrita) utilizados em diferentes situações sociais nas quais são produzidos, recebidos e interpretados por falantes, ouvintes, escritores e leitores, em contextos situacionais específicos de uso linguístico. Na teoria e na análise social do discurso, por sua vez, o termo costuma ser utilizado para designar os diferentes (e por vezes antagônicos) modos de estruturação das áreas de conhecimento e prática social, tanto em suas manifestações linguísticas quanto em outras formas simbólicas, como as imagens. Nessa acepção, para a maioria dos estudiosos dessas áreas, os discursos não só refletiriam ou representariam entidades e relações sociais, como as construiriam e as constituiriam.

[...] [Distintos] discursos constituem entidades-chave (sejam elas a "doença mental", a "cidadania" ou o "letramento") de diferentes modos e posicionam as pessoas de diversas maneiras como sujeitos sociais (por exemplo, como médicos ou pacientes), e são esses efeitos sociais do discurso que são focalizados na análise de discurso. Outro foco importante localiza-se na mudança histórica: como diferentes discursos se combinam em condições sociais particulares para produzir um novo e complexo discurso (FAIRCLOUGH, 2001, p. 22).

Nesse sentido, as filosofias e teorias políticas envolveriam discursos construídos acerca de elementos reais ou imaginários da situação política, econômica, social e cultural de determinada comunidade, país ou nação.

Tendo em vista o exposto acima, o objetivo deste trabalho é apresentar os principais elementos que compõem as teorizações sobre o discurso político presentes no pensamento de Ernesto Laclau e Slavoj Žižek para, a partir disso, delinear alguns dos diálogos e embates que suas posições suscitaram no que diz respeito ao discurso político e à prática política. Antes de passarmos às teorizações desses autores julgamos necessária uma revisão sucinta dos desenvolvimentos teóricos ocorridos na filosofia e nas ciências humanas e sociais que possibilitaram a esses pensadores formularem-nas.

\section{A ruptura linguística do século XX: do giro linguístico às teorias do discurso}


A partir de começos do século XX, houve um progressivo aumento na atenção dispensada à linguagem, tanto pela filosofia quanto pelas ciências humanas e sociais. Inicialmente isso se deveu a dois movimentos importantes que no começo do século $\mathrm{XX}$ buscaram romper com duas tradições bem estabelecidas nos estudos filológicos (a comparação das línguas e o estudo de sua evolução histórica) e filosóficos (a tradicional hegemonia exercida pela filosofia da consciência).

A ruptura com a tradição filológica iniciou-se com o linguista francês Ferdinand de Saussure e a publicação de sua obra póstuma intitulada Curso de Linguística Geral (1916). De acordo com Saussure, qualquer língua é um sistema de signos que só podem ser definidos uns em relação aos outros e não a partir de um referente externo ao sistema. O conjunto dessas relações formais comporia a estrutura da língua. Esse método de abordagem estrutural da linguagem inspirou pesquisas em outras áreas como psicologia, sociologia, matemática, antropologia etc., tornando-se muito popular em meados do século XX.

Por sua vez, a ruptura com a hegemonia da filosofia da consciência teve seus inícios com dois filósofos e matemáticos: o alemão Gottlob Frege e o britânico Bertrand Russell, cujas respectivas obras Sobre o Sentido e a Referência (1892) e Os Problemas da Filosofia (1913), contribuíram para deslocar as preocupações filosóficas de questões relacionadas ao mundo interior, privado, mental para o mundo exterior, público e objetivo das produções discursivas. Alguns autores afirmam que as problemáticas levantadas por Frege e Russell lançaram os fundamentos para o surgimento da posterior filosofia analítica, muito influente a partir da segunda metade do século XX.

A abordagem estrutural da linguagem proposta por Saussure é vista como o momento fundante do movimento estruturalista, que buscaria se constituir como um paradigma comum a todas as ciências e que motivou os defensores dessa abordagem a inspirarem discussões teóricas importantes em vários ramos do conhecimento. Por outro lado, é principalmente devido à filosofia analítica que o interesse pela linguagem nas ciências humanas e sociais tomou foi impulso.

De fato, seria a partir das publicações do Tratactus Logico-Philosophicus (1921) e de Investigações Filosóficas (1952), do filósofo e matemático austríaco Ludwig Wittgenstein (um pensador afinado com as ideias de Frege, de quem havia sido aluno) que as discussões sobre a linguagem passariam ao primeiro plano na filosofia ocidental. As ideias de 
Wittgenstein sobre a linguagem exerceram uma grande influência no meio filosófico e no conjunto das ciências humanas e sociais. $\mathrm{O}$ interesse suscitado pela linguagem ensejou a aparição de um movimento envolvendo um número considerável de estudiosos, dando origem à expressão giro linguístico (ou virada linguística), popularizada pelo filósofo norteamericano Richard Rorty no final da década de 1960.

\section{O giro linguístico}

A expressão giro linguístico foi bastante utilizada entre as décadas de 1970 e 1980 para se referir a um difuso e muito importante movimento intelectual que foi se articulando progressivamente ao longo do século XX, e que exerceu grande influência na Filosofia e em diversas Ciências Humanas e Sociais. Essa influência está relacionada a preocupações com o papel exercido pela linguagem não apenas nos projetos dessas disciplinas, mas também nos fenômenos geralmente estudados por elas. Ao modificar a concepção existente sobre a natureza da linguagem (de "palavra sobre o mundo" para "ação sobre o mundo"), o giro linguístico apontou questões relativas à natureza do conhecimento, questionando o que usualmente se entende por "realidade", e propiciou o surgimento de novos tipos de investigação e metodologias para sua análise. De acordo com Tomás Ibáñez Gracia, o giro linguístico romperia com uma tradição secular que estaria centrada no estudo do interior e privado "mundo das ideias", orientando a obra filosófica para o estudo dos enunciados linguísticos.

O "giro linguístico", portanto, substitui a relação "ideias/mundo" pela relação "linguagem/mundo" e afirma que para entender tanto a estrutura de nosso pensamento quanto o conhecimento que temos do mundo é preferível olhar para a estrutura lógica de nossos discursos em vez de esquadrinhar as interioridades de nossa mente. [O] [...] "giro linguístico" possibilitou, no transcurso de seu próprio desenvolvimento, uma segunda modificação de nossa concepção da linguagem. Essa deixou de ser vista como um meio para representar a realidade e passou a ser considerada um instrumento "para fazer coisas". Junto com suas funções "descritivo/representacionais" a linguagem iria adquirir, portanto, um caráter "produtivo" e se apresentava como, um elemento "formativo de realidades" (IBÁÑEZ GRACIA, 2004, pp. 46-47).

Além da influência sobre a filosofia e as ciências humanas e sociais, os desdobramentos teóricos iniciados a partir do giro linguístico possibilitaram a criação, o aprofundamento e a transformação de áreas como a linguística, a gramática e áreas afins.

Teorias do discurso 
Entre as décadas de 1960 e 1970, entre diversos linguistas, antropólogos, sociólogos, psicólogos e cientistas sociais que se debruçavam sobre a questão da linguagem, começou a haver um interesse não apenas pelas estruturas formais da língua ou pelo que cada elemento da linguagem poderia isoladamente representar. Durante as décadas seguintes houve um aumento progressivo aumento no interesse pela linguagem em uso e em interação com outros códigos, em como se articula no texto escrito e no discurso verbal, além de como se insere em um determinado contexto social e em uma determinada cultura. Esse conjunto de identidades relacionais, múltiplas e históricas, como vimos anteriormente, é chamado por alguns estudiosos de discurso. O campo necessariamente transdisciplinar dedicado ao estudo, teorização, aplicação e crítica que envolve esses elementos é geralmente chamado de análise ou teoria(s) do discurso. Os objetos de estudo abrangidos por esse campo são de natureza extremamente variada, incluindo o linguajar das culturas popular e erudita, os pronunciamentos feitos em paradas militares, documentos da administração pública, o vocabulário de manifestações políticas, etc. Em definitivo, segundo essa perspectiva, tudo o que envolve a linguagem pode ser analisado nos termos da construção das formas discursivas. Devido à popularização em décadas recentes desse tipo de análise da linguagem, alguns chegam a falar na existência de um "giro discursivo" na filosofia e nas ciências humanas e sociais.

Em muitos aspectos, o "giro linguístico", iniciado na filosofia e nas ciências sociais há várias décadas, poderia, hoje em dia, ser chamado de "giro discursivo" dado o atual e crescente interesse no estudo das formas do uso da linguagem e de conversações e textos, que vem substituindo o estudo do sistema abstrato ou da gramática de um idioma. Enquanto o estudo da gramática independente do contexto que, em um determinado momento, era proeminente, passou a se restringir quase que totalmente a uma pequena área da linguística, vemos que não só as demais áreas dessa disciplina como também a maioria das outras disciplinas nas humanidades e nas ciências sociais se voltaram para os problemas fascinantes do texto e da conversação em interação, cognição, contexto social ou cultura (DIJK, 2004, p. 7).

O percurso que fizemos nos possibilita entender melhor alguns desdobramentos da teoria política contemporânea. Em especial, a compreensão de como a linguagem, longe de ser um conjunto abstrato e isolado de signos, tem sido vista por alguns pensadores contemporâneos como constituidora de um sistema de significados e ações que "[...] condicionam a construção política da identidade" (TORFING, 2005, p. 153). Essa ideia nos será útil para o entendimento das teorizações de Laclau e Žižek sobre o discurso político e a ação política. 


\section{Identidade, linguagem e discurso}

Um dos fatores constitutivos da "identidade" em geral é sua construção a partir de um determinado discurso, cujos elementos estão em constante interação e simultânea determinação com o meio social. As identidades, assim como os discursos que as constituem, não são fixas e sofrem modificações ao longo do tempo devido a situações contingenciais, à realocação estratégia dos sujeitos em determinadas condições, ou mesmo à reconfiguração da conjuntura sociopolítica, econômica e cultural.

\section{Linguagem, identidade e pós-estruturalismo}

O estudo das relações entre discurso, linguagem e identidade foi dramaticamente afetado pelo advento da teoria pós-estruturalista (BELSEY, 2002, pp. 1-22). Tanto o pósmodernismo quanto o pós-estruturalismo são movimentos demasiado amplos e extremamente difíceis de serem definidos com precisão. Além disso, muitos daqueles que são apontados como sendo representantes de algum ou de ambos os movimentos, rejeitam a classificação. Não obstante, alguns dos nomes mais conhecidos que, com ou sem sua anuência, costumam ser identificados com o pós-modernismo e/ou com o pós-estruturalismo incluem Richard Rorty, Michel Foucault, Jacques Derrida, Jean Baudrillard, Jean-François Lyotard e Hayden White.

Obviamente, seria impossível detalhar aqui todas as contribuições teóricas de todos os pensadores relacionados de alguma maneira ao movimento pós-estruturalista para filosofia e para as ciências humanas e sociais. Destarte, nos limitaremos a citar um resumo feito pelo filósofo norte-americano Gary Gutting das principais críticas feitas ao estruturalismo pelos teóricos identificados com o pós-estruturalismo.

As críticas ao estruturalismo estão, tipicamente, baseadas em duas teses fundamentais: (1) nenhum sistema pode ser autônomo (autossuficiente) da forma que o estruturalismo exige; e (2) as dicotomias definidoras nas quais o sistema estruturalista está baseado expressam distinções que não se sustentam após uma cuidadosa análise. [...] Os pós-estruturalistas mantém a crítica estruturalista do sujeito, negando ao sujeito qualquer papel importante na fundação da realidade ou no conhecimento que podemos ter dessa realidade. Mas, em oposição ao estruturalismo, eles também rejeitam a ideia de que um sistema de pensamento possa ter qualquer fundamentação lógica (em sua coerência interna, por exemplo). Para os pós-estruturalistas, não existe nenhuma fundação de qualquer tipo que possa garantir a validade ou a estabilidade de qualquer sistema de pensamento. [...] Os filósofos pósestruturalistas têm se preocupado particularmente com as dicotomias fundamentais (ou oposições) subjacentes às teorias estruturalistas nas 
ciências humanas. A linguística de Saussure, por exemplo, baseia-se na distinção entre o significado e o significante; a antropologia dos mitos de Lévi-Strauss emprega oposições como cru/cozido, sol/lua e assim por diante. Em cada caso, os pós-estruturalistas argumentaram que a dicotomia não possui status absoluto porque as alternativas que oferece não são exclusivas nem exaustivas (GUTTING, 1998, p. 829).

Devido ao escopo limitado deste trabalho, faremos apenas uma rápida referência às implicações do pós-estruturalismo para a teoria do discurso.

\section{A teoria do discurso pós-estruturalista}

A teoria pós-estruturalista, entre outras coisas, colocou em xeque a cientificidade das humanidades ao questionar o discurso científico das ciências humanas e sociais, o discurso científico em geral e, finalmente, o próprio discurso. O surgimento da "teoria do discurso pósestruturalista" remete à década de 1980, sendo uma reação tanto ao determinismo estrutural e ao reducionismo econômico de algumas vertentes do marxismo (como o stalinismo), quanto ao individualismo metodológico. Ressalte-se que melhor seria que se falasse em "teorias" do discurso pós-estruturalista, uma vez que existe uma pluralidade de perspectivas, não havendo nenhum acordo entre os autores envolvidos com relação às ferramentas metodológicas, categorias analíticas ou quadro conceitual a serem utilizados para se contrapor àquelas abordagens.

No cerne da teoria do discurso pós-estruturalista está a concepção relacional de sociedade. Essa abordagem foi influenciada pela teoria relacional da linguagem do linguista estruturalista francês Ferdinand de Saussure. [...] Seguindo os insights da teoria linguística, a teoria do discurso pósestruturalista vê a sociedade como um sistema pelo de significado e discursivamente construído de relações diferenciais entre seus elementos constitutivos. Contudo, enquanto na teoria da linguagem de Saussure o significado de uma palavra é totalmente determinado pela sua localização relacional na estrutura de uma dada língua, a teoria do discurso pósestruturalista enfatiza que as ordens sociais nunca são totalmente estruturadas, mas abertas a intervenções políticas e deslocamentos que tornam impossível ligá-los a um fundamento último, daí a classificação de pós-estruturalista (PANIZZA; MIORELLI, 2013, p. 302).

Talvez o trecho mais utilizado quando se deseja apresentar de forma sumária a teoria do discurso estruturalista (para atacá-la ou defendê-la) seja a frase de Jacques Derrida recorrentemente citada: "Não há fora do texto" (DERRIDA, 1973, p. 194). Derrida queria dizer que não haveria algo para além do texto que pudesse lhe "fixar" o sentido. É preciso terse o cuidado, no entanto, para não entender essa passagem como uma espécie de negação da realidade exterior. 
A assertiva, desta forma isolada, pode surpreender. Ela costuma ser considerada como um relativismo absoluto, a negação de qualquer realidade "externa". Portanto, esclarecemos logo que se ela estivesse na negativa seria tão verdadeira quanto. A questão colocada é que se "lê" uma realidade a partir da cultura, da bagagem conceitual, de "textos" que remetem-se uns aos outros. Então, a realidade remete a textos e textos à realidade. [...] Não há dentro e fora absolutos, sendo a subjetividade e a objetividade enquadradas como funcionando dentro de um espaço topológico (QUADROS, 2009, p. 9).

Com efeito, os representantes da teoria do discurso pós-estruturalista não são ingênuos ou tolos a ponto de ignorarem a existência de realidade exterior à consciência. A ideia não é que todas as coisas sejam discursivas ou linguísticas, mas que para serem inteligíveis, precisam ser parte de um quadro mais amplo de significado, ou seja, um discurso. Em suma, segundo Jacob Torfing, a fundamentação da teoria do discurso pós-estruturalista estaria constituída por uma "[...] ontologia antiessencialista, a análise da forma linguística, a visão relacionalista e contextualista da formação da identidade, a asserção da primazia da política, e a epistemologia antifundacionista [...]" (TORFING, 2005, p. 155). Seria a partir desses elementos, ainda de acordo com Torfing, que autores como Laclau e Žižek teceriam suas análises sobre o discurso político, contribuindo para o desenvolvimento e a renovação da sociologia política: "Seu foco persistente em questões políticas como o poder, os movimentos sociais, o populismo, a democracia, e a emancipação, assim como sua dedicação à tentativa de avançar em novas maneiras de pensar e analisar essas questões, justificam um estudo aprofundado de seus pensamentos e ideias (TORFING, 2005, p. 155).

\section{Discurso político e ação política em Ernesto Laclau e Slavoj Žižek}

Nesta seção, iremos expor as teorizações a respeito do discurso político e da ação política em Ernesto Laclau e Slavoj Žižek. Para uma melhor organização do material, apresentaremos cada uma delas separadamente, começando por Laclau.

\section{A teoria do discurso de Laclau}

O cientista político argentino Ernesto Laclau, considerado um dos maiores expoentes da teoria política do discurso e fundador da teoria da hegemonia, é identificado com a perspectiva de análise intitulada pós-marxista. Tal perspectiva, que expressaria sua reorientação teórica, teria sido fundada com a publicação de uma de suas obras mais importantes, Hegemonia e estratégia socialista (1985), escrita em coautoria com a politóloga belga Chantal Mouffe. 
Costuma-se identificar influências diversas nas primeiras obras de Laclau: a desconstrução derridiana, o pós-estruturalismo lacaniano e a noção de hegemonia de Antonio Gramsci misturam-se a um marxismo de corte althusseriano. Posteriormente, durante sua evolução intelectual, o marxismo presente em seus primeiros escritos vai se dissipando para dar lugar a uma presença cada vez mais intensa da noção de que os sujeitos se autoconstituem através do discurso, do entendimento da linguagem como estruturadora da realidade, e do diálogo crítico com o pós-modernismo (FAIR, 2008, p. 13). De acordo com o autor, não teria havido uma descontinuidade radical em sua evolução intelectual, mas um processo de aprofundamento de intuições que "sempre" o acompanharam e a inscrição de novos problemas em uma determinada tradição de pensamento.

A ideia da política como hegemonia e articulação, por exemplo, é algo que sempre acompanhou minha trajetória política. [...] [Eu] nunca fui um marxista "total", alguém que busca no marxismo um "lar", uma visão completa e harmoniosa do mundo [...]. Os "jogos de linguagem" que joguei com o marxismo sempre foram mais complicados, e sempre trataram de articular o marxismo com algo distinto. [...] Não acredito que possas encontrar em meus escritos de nenhuma época a redução dos componentes não-classistas às superestruturas das classes. [...] De qualquer modo, [...] o importante foi a desconstrução do marxismo, não seu mero abandono. A perda da memória coletiva não é algo do qual alguém deva se alegrar. É sempre um empobrecimento e um fato traumático. Sempre se pensa a partir de uma tradição. É claro que a relação com a tradição não deve ser de submissão e repetição, e sim de transformação e crítica. Deve-se construir o próprio discurso como diferença em relação a essa tradição e isso implica, ao mesmo tempo, continuidades e descontinuidades. Se uma tradição cessa de ser o terreno cultural em que a criatividade e a inscrição de novos problemas têm lugar, e passa a ser, no lugar disso, um obstáculo para essa criatividade e essa inscrição, ela será gradual e silenciosamente abandonada (LACLAU, 1990, pp. 187-189).

De qualquer maneira, será justamente no livro escrito com Chantal Mouffe que a questão do discurso apareceria com mais vigor no pensamento de Laclau e onde seria delineada a noção de discurso que perpassaria toda a obra seguinte do autor. Para compreendê-la, é preciso ter noção do uso e da combinação que os autores fizeram de três noções: elemento, momento e prática articulatória.

No contexto desta discussão, chamaremos de articulação a toda prática que estabeleça uma relação tal entre elementos, que a identidade deles resulte modificada como resultado dessa prática. À totalidade estruturada resultante da prática articulatória, chamaremos de discurso. Chamaremos de momentos às posições diferenciais na medida em que aparecem articuladas no interior de um discurso. Inversamente, chamaremos de elementos a qualquer diferença que não se articula discursivamente (LACLAU; MOUFFE, 1987, p. 119). 
Em Laclau e Mouffe, os discursos são vistos como constituidores da realidade, no sentido de que não é possível apreender um fenômeno, de qualquer natureza, sem, ao mesmo tempo, entendê-lo sob sua forma discursiva.

Nossa análise rejeita a distinção entre práticas discursivas e não discursivas e afirma: a) que todo o objeto se constitui como objeto de discurso, na medida em que nenhum objeto se dá fora de toda superfície discursiva de emergência; b) que toda distinção entre os que usualmente são denominados aspectos linguísticos e práticos (de ação) de uma prática social, ou são distinções incorretas, ou devem ter lugar como diferenciações internas à produção social de sentido, que se estrutura sob a forma de totalidades discursivas (LACLAU; MOUFFE, 1987, p. 121).

Um incêndio na mata provocado por um raio, por exemplo, só seria inteligível em se associando elementos como chuva, eletricidade, calor, faísca, chama, fogo, combustão etc. Destarte, qualquer enunciado só poderia ser entendido em uma determinada cadeia discursiva relacional articulada de significados.

\section{Discurso e ação política em Laclau}

Contudo, como reconhece Laclau, o estabelecimento de uma cadeia discursiva relacional articulada de significados não ocorre de maneira tão simples quando se trata de discurso de natureza ética, moral ou política. Nesses casos, o poder que cada significado possui nas condições de sua emergência - presente de maneira menos intensa na descrição de fenômenos naturais - é um elemento de fulcral importância. No âmbito da ética, da moral ou da política lutariam por estabelecerem verdades e excluírem outros significados do campo da significação.

Se dificilmente, em uma época histórica temos dois discursos diametralmente opostos que disputam a significação científica dos fenômenos da natureza, isto, de forma distinta, acontece quase como decorrência de sua natureza no discurso político. O papel do Estado nas sociedades ocidentais contemporâneas é um significado em disputa: associálo a um estado mínimo ou ao um Estado provedor, não se trata de uma questão de superestrutura ou uma decorrência de uma lógica econômica, mas é uma forma de constituí-lo enquanto Estado com todas as suas cargas, decorrências e consequências para os sujeitos concretos, efeitos de uma ou outra construção. O que deve ficar claro aqui é que o discursivo não se encontra em um nível superestrutural ou das ideias. Não é possível distinguir entre o "Estado real" e o "Estado discursivo". O primeiro só pode ser apreendido em um discurso. Em qualquer sociedade haverá sempre uma disputa entre discursos que significam o estado, o que é diferente de dizer que estes discursos disputam um estado não significado (PINTO, 1999, p. 40).

Levando-se em conta o trecho acima, retomaremos a ideia de prática articulatória que, 
a nosso ver, é essencial para o entendimento do discurso político em Laclau. Se o discurso é uma totalidade estruturada pela prática articulatória entre significados muitas vezes antagônicos, isso quer dizer que ele possui uma existência necessariamente provisória, contingencial, e que pode se alterar segundo as circunstâncias ou mudanças conjunturais. Em outras palavras, é a própria incompletude que permite ao discurso se constituir.

Acreditamos ter chegado aqui ao ponto fundamental da ideia de discurso político em Laclau. Se o discurso político só pode se constituir na incompletude, seu significado é temporário. Um discurso político não pode nunca chegar a um consenso permanente ou à universalidade. A prática política e o discurso político só sobrevivem no antagonismo, não na completude, não no consenso, não na universalidade. Por isso, para Laclau, a ideia de "emancipação" seria algo impraticável e definitivamente equivocada, uma vez que implicaria a resolução última de todos os conflitos, de todos os antagonismos (LACLAU, 1996, pp. 1141). Enquanto o antagonismo constituiria a essência da política, a completude seria o seu fim - o que para Laclau, equivaleria ao próprio fim das relações sociais (MENDONÇA, 2008, p. 64). Cremos que essa argumentação que reconhece a pluralidade de antagonismos que operam na sociedade está em consonância com a defesa, por parte de Laclau, de um projeto de “democracia plural e radical”. Para ele, a tarefa da esquerda não poderia "[...] consistir em renegar a ideologia liberal-democrática, mas sim o contrário, em aprofundá-la e expandi-la na direção de uma democracia radicalizada e plural” (LACLAU, 1987, p. 199).

\section{A noção de discurso em Žižek}

O filósofo e psicanalista esloveno Slavoj Žižek é um dos intelectuais que se encontram em maior evidência na atualidade. Para além de seu estilo combativo, polêmico, irônico, eloquente e "midiático", talvez isso se deva ao fato de que sua vasta obra versa sobre temas muito variados, que vão da teologia à filmologia, passando pela ética em Kant e a questão do inconsciente na psicologia e na psicanálise.

Žižek é tido, com justa razão, como um pensador pouco sistemático. Suas obras mesclam erudição com metáforas ambíguas e referências a elementos do que se costuma chamar de "cultura popular". Entretanto, ainda que seja muito difícil definir os paradigmas de seu pensamento, podemos apontar que entre as principais influências identificáveis na obra do autor se encontram a apropriação de parte significativa da psicanálise lacaniana (especialmente a que se refere ao sujeito e as relações entre real, imaginário e simbólico), uma 
releitura da dialética hegeliana, o diálogo com o materialismo marxista e uma postura muito crítica (embora aberta ao diálogo) com o pós-estruturalismo (DALY, 2004, pp. 1-22).

De qualquer maneira, Žižek não pode ser classificado como um "teórico do discurso". Na verdade, o filósofo é um crítico de uma certa tradição filosófica para a qual o papel da filosofia seria o de proceder a uma análise discursiva da linguagem que buscasse "desvelar" o conteúdo das relações sociais, do mundo etc. Diga-se de passagem que um dos alvos do autor é a análise do discurso foucaultiana, que ele vê como inconsistente por, entre outras coisas, falhar em teorizar o princípio gerador das formações sociossimbólicas e desprezar o papel da ideologia - noção central para Žižek (VIGHI; FELDNER, 2007, p. 142).

\section{Discurso e ação política em Žižek}

Somente é possível o entendimento de como Žižek concebe o discurso político e a ação política reconhecendo a grande importância que o autor dá à questão da ideologia. Segundo ele, essa questão tão central teria sido deixada de lado por parte da filosofia política contemporânea. Žižek define a ideologia como sendo a "[...] matriz geradora que regula a relação entre o visível e o invisível, o imaginável e o inimaginável, bem como as mudanças nessa relação" (ŽIŽEK, 1999b, p. 7). O autor rejeita a ideia de que a ideologia seja uma falsa consciência ou uma representação ilusória da realidade. Baseando-se simultaneamente em Lacan e Hegel, e tendo como alvo principal o entendimento da teoria crítica (especialmente a habermasiana) sobre a ideologia, Žižek sustenta que seria a realidade mesma é que deveria ser concebida como ideológica. Para ele,

[...] "ideológica” é uma realidade social cuja a própria existência implica o não conhecimento de sua essência por parte de seus participantes, ou seja, a efetividade social cuja a própria reprodução implica que os indivíduos "não sabem o que fazem". "Ideológica" não é a "falsa consciência" de um ser (social), mas esse próprio ser, na medida em que ele é sustentado pela "falsa consciência" (ŽIŽEK, 1999a, pp. 305-306).

Tendo exposto brevemente suas tematizações sobre a ideologia, podemos agora ter uma noção melhor de como ele concebe o discurso e a ação política. De acordo com Sandro Bezzanela, existiriam dois "momentos" da "filosofia política" de Žižek que se articulam para dar-lhe sustentação teórica.

Num primeiro momento, numa crítica contundente à hegemonia da democracia liberal do capitalismo global contemporâneo que cerceia o debate político ao determinar o bem e o mal, ao negar às pessoas a possibilidade do exercício da liberdade de escolha e, consequentemente, a 
responsabilizar-se pelos riscos de suas opções, uma vez que as escolhas estão enquadradas e delimitadas por uma margem administrativa de segurança. Assim, Žižek apresenta-nos a contradição do discurso ideológico próprio da democracia liberal do capitalismo global, que apregoa a liberdade como imperativo a ser alcançado por indivíduos, povos e nações, mas que se apresentam na concretude dos fatos de maneira proibitiva, cerceadora e punitiva para aqueles indivíduos, povos e nações que se aventurarem na busca da liberdade de pensamento e ação (BEZZANELA, 2009, pp. 18-19).

Para Žižek, portanto, o discurso ideológico do capitalismo globalizante, que supostamente exalta a liberdade, encobre as restrições ao exercício dessa liberdade, uma vez que as escolhas se dão entre opções controladas e definidas de antemão pelo próprio sistema que, em definitivo, eliminam qualquer antagonismo verdadeiramente sincero. Além disso, como destacado por Bazzanela, Žižek também critica a "falência das esquerdas" ainda presas a modelos conceituais equivocados, o que se manifesta em sua incapacidade de dar respostas às demandas das sociedades contemporâneas e que acaba por reforçar o sistema que afirmam combater.

Um segundo momento de sua filosofia política, apresenta-se como uma crítica às esquerdas e as suas dificuldades de atualização conceitual, interpretativas e de ação, em relação às mudanças do capitalismo global contemporâneo. [...] Com dificuldades de superarem certas ortodoxias marxistas, ainda atônitos com a queda do muro ou com profecias sobre o "fim da história", de certa forma deslumbrados e envoltos com o discurso da democracia liberal do capitalismo global, agarram-se como náufragos em titânica batalha de sobrevivência a propostas anacrônicas ou equivocadas, reforçando o discurso fundamentalista do capitalismo global e sua democracia liberal (BEZZANELA, 2009, p. 19).

Citando os trabalhos do filósofo marxista húngaro György Lukács, Žižek defende que a crítica da ideologia só pode ser empreendida de maneira consequente levando-se em conta dois aspectos constitutivos da sociedade capitalista: a luta de classes e a questão da mercadoria.

[...] [Um] dos maiores e mais permanentes resultados do assim chamado "marxismo ocidental" formulado inicialmente pelo jovem Lukács é que a estrutura classe-e-mercadoria do capitalismo não é apenas um fenômeno limitado ao "domínio" particular da economia, mas o princípio estruturante que sobredetermina a totalidade social, da política à arte e à religião. Essa dimensão global do capitalismo é suspensa na política progressista multiculturalista de hoje: seu "anticapitalismo" é reduzido ao nível de como o capitalismo de hoje alimenta a opressão sexista, racista e assim por diante (ŽIŽEK, 2000, p. 93).

No final do trecho selecionado, Žižek deixa implícita a orientação que devem ter o discurso político e a prática política: seu sentido deve ser o da superação dos "traços 
estruturantes" do capitalismo.

\section{Diálogos e embates entre Ernesto Laclau e Slavoj Žižek}

Iremos agora apresentar algumas das polêmicas que envolveram os autores. Como vimos, as posições assumidas por Ernesto Laclau e Slavoj Žižek no que diz respeito ao discurso político e à ação política são díspares e os autores já travaram debates interessantes no âmbito da ciência política. Para esta parte utilizaremos principalmente os textos incluídos no trabalho conjunto feito por Laclau, Žižek e pela filósofa pós-estruturalista especialista em estudos de gênero, Judith Butler, intitulado Contingency, Hegemony, Universality: Contemporary Dialogues on the Left (2000). Antes de analisarmos os embates entre os autores, julgamos necessário que seja destacado o maior ponto de convergência entre eles. Tanto Laclau e Žižek estão de acordo na valorização do antagonismo como algo extremamente positivo no discurso político e na prática política.

No texto Class Struggle or Postmodernism? Yes, please!, entre outros pontos, Žižek primeiro rejeita as "falsas alternativas" ao sistema capitalista e em seguida discute suas divergências político-filosóficas com Laclau e Butler. Žižek inicialmente afirma sua proximidade ao conceito de antagonismo, tão caro a Laclau.

Para começar, gostaria de enfatizar minha proximidade a [...] uma noção central [...] [no trabalho de Ernesto Laclau] que eu endosso totalmente, acho-a extraordinariamente produtiva. [...] [É] a noção de antagonismo como fundamentalmente diferente da lógica da diferença simbólica/estrutural e a concomitante noção de luta hegemônica para preencher o lugar vazio da universalidade como necessária/impossível (ŽIŽEK, 2000, p. 91).

Contudo, ao que parece, o acordo entre os autores terminava aí. Para Laclau, como a plenitude da sociedade seria algo inalcançável, a atividade política deveria orientar-se pela busca de uma democracia cada vez mais radical e plural. Ao longo desse esforço, afirma o autor, alguns problemas parciais da sociedade iriam sendo paulatinamente solucionados.

Se hegemonia significa a representação, por um setor social particular, de uma totalidade impossível [...], então basta que façamos o espaço de substituições tropológicas totalmente visível para permitir que a lógica hegemônica opere livremente. Se a plenitude da sociedade é inatingível, as tentativas de alcançá-la irão necessariamente falhar, embora sejam capazes, na busca desse objeto impossível, de resolver uma variedade de problemas parciais [...] (LACLAU, 2001, p. 244).

Žižek, por sua vez, criticava Laclau por considerar que a posição do argentino 
implicava a resignar-se a alcançar resultados demasiadamente limitados. Aceitar a impossibilidade da totalidade poderia dar lugar a um questionamento muito mais profundo: o de rompimento com o princípio estrutural que fundamenta toda a sociedade atual.

Que tal mudar o próprio princípio estrutural fundamental da sociedade, como aconteceu com o surgimento da "invenção democrática"? A passagem da monarquia feudal para a democracia capitalista, ao mesmo tempo que não conseguiu chegar à "plenitude impossível da sociedade", certamente fez mais do que apenas "resolver uma variedade de problemas parciais" (ŽIŽEK, 2000, p. 93).

Com respeito a essa crítica, Laclau afirmou que é Žižek quem estaria a querer, equivocadamente, reduzir sua posição a um mero gradualismo que se fecha em si mesmo. Laclau concordava que demandas políticas e sociais poderiam ser descontínuas no sentido de que uma não necessariamente evolveria as outras. Contudo, repudiava a ideia de que pudessem ser satisfeitas politicamente tão somente através de um processo gradual que lidasse com elas em separado, uma de cada vez.

Se, por exemplo, a relação de equivalência se estabelece entre uma pluralidade de demandas sociais, a satisfação de qualquer uma delas vai depender da construção de um imaginário social mais global, cujos efeitos serão muito mais sistêmicos do que qualquer coisa que um mero gradualismo poderia prever. De fato, o "gradualismo" é a primeira das utopias: a crença de que há um centro administrativo neutro que possa lidar com as questões sociais de uma maneira não-política. Se pensarmos nas maiores transformações de nossas sociedades no século XX, vemos que as reformas "parciais", em todos os casos, fizeram-se possíveis apenas através de alterações significativas em imaginários sociais mais globais - pense no New Deal, no Welfare State, e, em anos mais recentes, [...] no neoliberalismo; mas, eu argumentaria, que algo não muito diferente poderia ser dito dos processos cujos efeitos são certamente mais globais e sistêmicos, tal como a Revolução Russa (LACLAU, 2000, pp. 197-198).

Laclau julgava que a posição de Žižek era frágil por nunca definir o que entendia por “abordagem global da política". Isso o levava a opor soluções parciais no interior de um horizonte com mudanças no próprio horizonte. As coisas complicavam-se ainda mais porque Žižek tampouco definia o que seria esse horizonte e a lógica de sua constituição (se um terreno do social ou uma constituição imaginária que totalizava uma pluralidade de lutas distintas, por exemplo). Laclau condenava ainda que Žižek recorresse a Lukács, a quem o argentino considerava "a quintessência do reducionismo de classe" (LACLAU, 2000, p. 198).

Continuando com a polêmica, para Žižek, o capitalismo seria capaz de se acomodar às demandas das políticas identitárias reclamadas por Butler, resolver todos os "problemas parciais" aos quais se referia Laclau e, ainda assim, continuar a explorar economicamente o 
grupo que pretensamente teria alcançado sua "libertação". Contudo, uma das questões essenciais para Žižek, a da classe social, permaneceria intocada. Recorrendo ao filósofo francês Alain Badiou e à cientista política norte-americana Wendy Brown, ele acusava a política pós-moderna e, por extensão, também a Laclau de "se esquecerem" dessa questão.

Portanto, na medida em que a política pós-moderna envolve uma "retirada teórica do problema da dominação no capitalismo", é aqui, nesta suspensão silenciosa da análise de classe, que estamos lidando com um caso exemplar do mecanismo de deslocamento ideológico: quando o antagonismo de classe é negado, quando seu papel fundamental de estruturação é suspenso, "outras variáveis indicativas de diferença social podem vir a ter um peso excessivo; de fato, elas podem carregar todo o peso dos sofrimentos produzidos pelo capitalismo em adição àquele atribuível de maneira explícita à condição politizada". Em outras palavras, esse deslocamento explica a maneira algo "excessiva" com que o discurso político da política identitária pós-moderna insiste nos horrores do sexismo, racismo, e assim por diante - esse "excesso" vem do fato de que esses outros "-ismos" têm de suportar o excedente do investimento da luta de classes, cuja extensão não é reconhecida (ŽIŽEK, 2000, p. 97).

Em suma, para o autor, não bastaria, portanto a luta por uma democracia mais plural e radical. A maneira de se combater a despolitização seria pensar o impossível, ousar pensar um mundo diferente. Uma luta em prol da superação do capitalismo e dos valores e limites impostos pela sociedade democrática-liberal que, de acordo com Žižek, teriam sido abraçados por Laclau e grande parte da esquerda mundial.

Com respeito a essas últimas críticas e considerações, Laclau foi bastante ácido em sua réplica a Žižek. Primeiramente, ele afirmou que compartilhava das preocupações do esloveno com a política pós-moderna centrada em questões identitárias e com o comportamento da esquerda no mundo contemporâneo, mas acusou Žižek de estruturar seu discurso valendo-se de "entidades fetichizadas" como classe, luta de classes e capitalismo, que não possuiriam nenhum significado preciso. Isso estaria relacionado, segundo Laclau, ao fato de Žižek dizerse marxista, mas não prestar nenhuma atenção à história intelectual do marxismo, inclusive virtualmente desconhecendo referências importantes como Gramsci, ou o austromarxismo. Além disso, Laclau criticou Žižek pelo fato de que propunha a superação do capitalismo democrático-liberal sem especificar o que gostaria que fosse colocado em seu lugar. Isso faria com que seu discurso anticapitalista não passasse de "conversa fiada". Graças a suas “ferramentas lacanianas” e sua própria reflexão, Žižek teria avançado consideravelmente em áreas como a compreensão dos processos ideológicos nas sociedades contemporâneas, mas ficado preso a categorias muito tradicionais no que se referia a seu pensamento estritamente 
político (LACLAU, 2000, p. 206).

\section{Considerações finais}

Como vimos, apesar de alguns pontos de acordo, que inclusive permitem que ambos se situem no campo da esquerda, Ernesto Laclau e Slavoj Žižek entendiam o discurso político de maneira distinta, interpretavam de forma bastante um tanto quanto diversa o momento político de começos da década de 2000 e, sobretudo, divergiam significativamente a respeito de quais caminhos deveriam ser trilhados pela esquerda contemporânea. É certo que em um trabalho tão curto não seria possível abordar exaustivamente a polêmica travada entre os dois pensadores. Polêmica aliás, precocemente interrompida pela morte de Laclau em setembro de 2014.

Mas se tanto a busca por uma democracia radical e plural quanto por uma democracia que proponha como horizonte algo para além dos limites da sociedade capitalista-liberaldemocrática necessitam do antagonismo para constituírem-se enquanto discurso político que mobiliza a prática política, acreditamos que essa divergência é salutar e pode render bons frutos nesses campos. Além disso, esse é um tema de grande relevância para todos aqueles que se interessam pelo estudo da sociologia política. 


\section{Referências}

BAZZANELA, Sandro. Os pressupostos da filosofia política de Savoj Žižek. In: GUERRA, Elizabete; Teles, Idete Teles (orgs.) Lacunas do real: leituras de Slavoj Žižek. Florianópolis: NEFIPO, 2009.

BELSEY, Catherine. Poststructuralism: a very short introduction. Oxford: Oxford University Press, 2002.

DALY, Glyn. Introduction: Risking the Impossible. In: ŽIŽEK; Slavoj; D ALY, Glyn. Conversations with Žižek. Oxford: Polity Press, 2004.

DERRIDA, Jacques [1967]. Gramatologia. São Paulo: Perspectiva, 1973.

DIJK, Teun A. van. O giro discursivo. In: IÑIGUEZ, Lupicinio (org.). Manual de análise do discurso em ciências sociais. Petrópolis: Vozes, 2004.

FAIR, Hernán. Laclau y Verón: discusiones teóricas y contribuciones para la praxis en dos teorías del discurso. In: Estudios de Filosofía Práctica e Historia de las Ideas. Ano 9, $n^{\circ} 10$, dezembro 2008. Disponível em

$<$ http://www.scielo.org.ar/scielo.php?script=sci_arttext\&pid=S1851-94902008000100001>. Acesso em 18/09/2016.

FAIRCLOUGH, Norman [1992]. Discurso e mudança social. Brasília: Editora Universidade de Brasília, 2001.

GUTTIN, Gary. Post-Structuralism. In: CRAIG, Edward (ed.). The Shorter Routledge Encyclopedia of Philosophy. Routledge. Nova York, 1998.

IBÁÑEZ GRACIA, Tomás. O “giro linguístico". In: IÑIGUEZ, Lupicinio (org.). Manual de análise do discurso em ciências sociais. Petrópolis: Vozes, 2004.

LACLAU, Ernesto. Más allá de la emancipacición. In: Emancipación y diferencia.

Buenos Aires: Ariel, 1996. Visión, 1990.

. Nuevas reflexiones sobre la revolución de nuestro tiempo. Buenos Aires: Nueva

Structure, History and the Political. In: BUTLER, Judith Butler, LACLAU, Ernesto, ŽIŽEK, Slavoj. Contingency, Hegemony, Universality: Contemporary Dialogues on the Left. Nova York: Verso, 2000.

The Politics of Rhetoric. In: COHEN, Tom; COHEN, Barbara; MILLER, J. Hillis; Warminski, Andrzej (eds.). Material events: Paul de Man and the afterlife of theory. Minneapolis: University of Minnesota Press, 2001.

LACLAU, Ernesto; MOUFFE, Chantal [1985]. Hegemonía y estrategia socialista: Hacia una radicalización de la democracia. Madrid: Siglo XXI, 1987.

MENDONÇA, Daniel de. A impossibilidade da emancipação: notas para uma política democrática radical. In: MENDONÇA, Daniel de; RODRIGUES, Léo Peixoto (orgs.). Pós- 
estruturalismo e teoria do discurso: em torno de Ernesto Laclau. Porto Alegre: EDIPUCRS, 2008.

PANIZZA, Francisco; MIORELLI, Romina. Taking Discourse Seriously: Discursive Institutionalism and Post-structuralist Discourse Theory. In: Political Studies 2013 vol. 61, issue 2, pp. 301-318. Disponível em <http://onlinelibrary.wiley.com/doi/10.1111/j.14679248.2012.00967.x/abstract>. Acesso em 18/09/2016.

PINTO, Célia Regina Jardim. Notas a respeito de Ernesto Laclau. In: Revista de Ciencias Sociales, v. 15. Montevidéu, 1999. Disponível em

$<$ http://cienciassociales.edu.uy/departamentodesociologia/wpcontent/uploads/sites/3/2013/archivos/Notas\%20a\%20prop\%C3\%B3sito\%20de\%20Ernesto\% 20Laclau.pdf >. Acesso em 18/09/2016.

QUADROS, Eduardo Gusmão de. Gramatologia e crítica histórica. In: Revista de Teoria da História Ano 1, Número 2, dezembro/ 2009. Disponível em $<$ https://www.revistas.ufg.br/teoria/article/view/28460>. Acesso em 18/09/2016.

TORFING, Jacob. New Theories of Discourse: Laclau, Mouffe and Žižek. Oxford: Blackwell Publishers, 1999.

Poststructuralist Discourse Theory: Foucault, Laclau, Mouffe, and Žižek. In: JANOSKI, Thomas; ALFORD, Robert R.; HICKS, Alexander M.; SCHWARTZ, Mildred A. (eds.). The Handbook of Political Sociology: States, Civil Societies, and Globalization. Cambridge: Cambridge University Press, 2005.

VIGHI, Fabio; FELDNER, Heiko. Ideology Critique or Discourse Analysis?: Zizek against Foucault. In: European Journal of Political Theory 6 (2). Londres: SAGE, 2007. Disponível em <http://ept.sagepub.com/content/6/2/141>. Acesso em 18/09/2016.

ŽIŽEK, Slavoj. Class Struggle or Postmodernism? Yes, please!. In: BUTLER, Judith Butler, LACLAU, Ernesto, ŽIŽEK, Slavoj. Contingency, Hegemony, Universality: Contemporary Dialogues on the Left. Nova York: Verso, 2000.

Como Marx inventou o sintoma? In: . (org.) [1994]. Um mapa da ideologia. Rio de Janeiro: Contraponto, 1999a.

O espectro da ideologia. In: (org.) [1994]. Um mapa da ideologia. Rio de Janeiro: Contraponto, 1999b.

Recebido em 18-09-2016; Revisado em 27-07-2018; Publicação em 15-12-2018. 